\title{
Intra-observer, inter-experiment and inter-observer variability of left ventricular volumes and mass measurements in mice using an 11.7 Tesla MRI
}

\author{
Laetitia Vanhoutte ${ }^{1,2^{*}}$, Olivier Feron', Jean-Luc Balligand ${ }^{1}$, Bernard Gallez ${ }^{3}$, Hrag Esfahani ${ }^{1}$, Stéphane Moniotte ${ }^{2}$ \\ From 16th Annual SCMR Scientific Sessions \\ San Francisco, CA, USA. 31 January - 3 February 2013
}

\section{Background}

In cardiovascular research, there is an increasing interest in high-field MRI to characterize cardiac anatomy and function in small rodents. However, data on reproducibility of the method are scarce. Our aim was to evaluate the intra-observer, inter-experiment and inter-observer variability of left ventricular (LV) mass and volumes measurements in mice using an 11.7T MRI scanner.

\section{Methods}

Seven 10 weeks-old C57Bl6J male mice were studied, including 4 animals with a surgical transverse aortic constriction in order to produce cardiac hypertrophy. 3 were sham (control) mice.

During the entire procedure, animals were anaesthetized with Isoflurane 1-3\%, in a temperature-controlled setting. Scan were retrospectively gated for electrocardiogram (ECG) and respiration. Imaging was performed on a 11.7 Tesla Bruker MR scanner. Cardiac scout images were obtained in the conventional planes with a tripilot sequence. A 2D cine FLASH sequence was applied to acquire a set of 7 contiguous short axis images covering the entire ventricles, perpendicular to the LV long axis. One day after the procedure, mice were scanned again under the same conditions.

The LV systolic function was assessed from each stack of images by tracing epicardial and endocardial borders, including papillary muscles, on the Segment software (Medviso, Sweden). End-diastolic (EDV), end-systolic $(\mathrm{ESV})$ and stroke volume (SV) were determined ( $\mu \mathrm{l})$. LV ejection fraction (EF, in \%) and LV mass (mg) were subsequently deduced. One stack of images was analyzed twice by the same person, and once by an independent observer.

\section{Results}

Accurate quantitative data were obtained in all animals. The Table 1 lists the mean \pm SD values and the Bland-Altman and Pearson analysis results. The best reproducibility was obtained for the measurements of LV mass and EDV, with a coefficient of variability (Cov) between 1.70 and $12 \%$. More variation was found in ESV measurement (CoV 1-70-22.40\%). Results for SV and EF were the less reproducible, with a CoV between 14.52 and $31.45 \%$. The Pearson correlation coefficient indicates good correlation between all methods for all parameters ( $\mathrm{r}$ square between 0.81 and 0.99 ), except for the SV, particularly in terms of inter-experiment reproducibility (r square $=0.03$ ).

\section{Conclusions}

In our hands, reproducibility was excellent for LV mass and EDV, good for ESV and EF to a lesser extent, and more limited for the stroke volume, with a bad inter-observer correlation. This highlights the need to interpret our results by taking into account these limitations, focusing on more reproducible parameters when interpreting data.

\section{Funding}

This work was supported by grants from the Fonds de la Recherche Scientifique FRS-FNRS.

\footnotetext{
${ }^{1}$ FATH, UCL, Brussels, Belgium

Full list of author information is available at the end of the article
} 
Table 1 Intra-observer, inter-experiment and inter-observer variability analysis.

\begin{tabular}{|c|c|c|c|c|c|}
\hline Intraobserver variability & LV mass & EDV & ESV & SV & $\mathrm{EF}$ \\
\hline Mean \pm SD data 1 & $93,00 \pm 8,018$ & $76,57 \pm 6,629$ & $42,14 \pm 8,606$ & $34,29 \pm 2,792$ & $47,86 \pm 6,674$ \\
\hline Mean \pm SD data 2 & $93,71 \pm 7,643$ & $76,86 \pm 6,857$ & $40,00 \pm 10,04$ & $37,14 \pm 3,744$ & $52,43 \pm 8,569$ \\
\hline Bias & $-0,7143$ & $-0,2857$ & 2,143 & $-2,8571$ & $-4,5714$ \\
\hline Limits of agreement & $-12,62$ to 11,19 & $-3,990$ to 3,418 & $-11,55$ to 15,84 & $-15,43$ to 9,715 & $-23,23$ to 14,09 \\
\hline SDD & 6,07 & 1,89 & 6,99 & 6,41 & 9,52 \\
\hline Coefficient of variability & $6,51 \%$ & $2,46 \%$ & $1,70 \%$ & $17,96 \%$ & $18,98 \%$ \\
\hline r square & 0,92 & 0,99 & 0,92 & 0,58 & 0,84 \\
\hline Interexperiment variability & LV mass & EDV & ESV & SV & $\mathrm{EF}$ \\
\hline Mean \pm SD data 1 & $93,00 \pm 8,018$ & $76,57 \pm 6,629$ & $42,14 \pm 8,606$ & $34,29 \pm 2,792$ & $47,86 \pm 6,674$ \\
\hline Mean \pm SD data 3 & $96,43 \pm 7,970$ & $73,14 \pm 7,557$ & $41,29 \pm 9,526$ & $31,71 \pm 3,834$ & $47,14 \pm 7,658$ \\
\hline Bias & $-3,429$ & 3,429 & 0,8571 & 2,571 & 0,7143 \\
\hline Limits of agreement & $-20,70$ to 13,84 & $-13,46$ to 20,32 & $-13,25$ to 14,96 & $-8,450$ to 13,59 & $-12,80$ to 14,23 \\
\hline SDD & 8,81 & 8,619 & 7,198 & 5,623 & 6,897 \\
\hline Coefficient of variability & $9,64 \%$ & $12 \%$ & $17,25 \%$ & $17,04 \%$ & $14,52 \%$ \\
\hline r square & 0,83 & 0,81 & 0,92 & 0,71 & 0,89 \\
\hline Interobserver variability & LV mass & EDV & ESV & SV & EF \\
\hline Mean \pm SD data 2 & $93,71 \pm 7,643$ & $76,86 \pm 6,857$ & $40,00 \pm 10,04$ & $37,14 \pm 3,744$ & $52,43 \pm 8,569$ \\
\hline Mean \pm SD data 4 & $95,14 \pm 8,379$ & $67,57 \pm 7,593$ & $34,29 \pm 7,296$ & $33,57 \pm 1,360$ & $52,71 \pm 5,384$ \\
\hline Bias & $-1,43$ & 9,29 & 5,71 & 3,57 & $-0,29$ \\
\hline Limits of agreement & $-12,57$ to 9,71 & $-1,43$ to 20,00 & $-10,59$ to 22,02 & $-18,22$ to 25,36 & $-22,16$ to 21,59 \\
\hline SDD & 5,48 & 5,47 & 8,32 & 11,12 & 11,16 \\
\hline Coefficient of variability & $6,02 \%$ & $8 \%$ & $22,40 \%$ & $31,45 \%$ & $21,23 \%$ \\
\hline r square & 0,94 & 0,93 & 0,97 & 0,03 & 0,84 \\
\hline
\end{tabular}

\section{Author details}

${ }^{1}$ FATH, UCL, Brussels, Belgium. ${ }^{2}$ Pediatrics, UCL, Brussels, Belgium. ${ }^{3}$ REMA,

UCL, Brussels, Belgium.

Published: 30 January 2013

doi:10.1186/1532-429X-15-S1-P282

Cite this article as: Vanhoutte et al:: Intra-observer, inter-experiment and inter-observer variability of left ventricular volumes and mass

measurements in mice using an 11.7 Tesla MRI. Journal of Cardiovascular

Magnetic Resonance 2013 15(Suppl 1):P282.

\section{Submit your next manuscript to BioMed Central} and take full advantage of:

- Convenient online submission

- Thorough peer review

- No space constraints or color figure charges

- Immediate publication on acceptance

- Inclusion in PubMed, CAS, Scopus and Google Scholar

- Research which is freely available for redistribution

Submit your manuscript at www.biomedcentral.com/submit 